Advances in Dynamical Systems and Applications.

ISSN 0973-5321, Volume 16, Number 1, (2021) pp. 181-188

(C) Research India Publications

https://dx.doi.org/10.37622/ADSA/16.1.2021.181-188

\title{
Soil Enrichment and Crop Yield Enhancement Technique
}

\begin{abstract}
Aleksei V. Rusinov
Candidate of Engineering Sciences, associate professor, Department of Technosphere Safety and Transport and Technological Machines, Faculty of Engineering and Environmental Management, FSBEI HE N.I. Vavilov Saratov State Agrarian University, Saratov, Russia. 410056 Saratov, Sovetskaya Str. 60.
\end{abstract}

\section{Oleg V. Kabanov}

Candidate of Engineering Sciences, associate professor, Department of Technosphere Safety and Transport and Technological Machines, Faculty of Engineering and Environmental Management, FSBEI HE N.I. Vavilov Saratov State Agrarian University, Saratov, Russia. 410056 Saratov, Sovetskaya Str. 60.

\author{
Vladimir V. Sliusarenko \\ Doctor of Engineering Sciences, \\ Professor \\ Chistaia Planeta MC LLC \\ 410002 Russia, Saratov, Chernyshevskogo \\ Str. 124, office 102,
}

\begin{abstract}
Tatiana V. Fediunina
Candidate of Engineering Sciences, associate professor,

Department of Environmental Engineering, Construction and Heat Power Engineering, Faculty of Engineering and Environmental Engineering, FSBEI HE N.I. Vavilov Saratov State Agrarian University, Saratov, Russia. 410056 Saratov, Sovetskaya Str. 60.
\end{abstract}

\section{Dmitrii A. Rusinov}

Postgraduate student

Department of Environmental Engineering, Construction and Heat Power Engineering, Faculty of Engineering and Environmental Engineering, FSBEI HE N.I. Vavilov Saratov State Agrarian University, Saratov, Russia. 410056 Saratov, Sovetskaya Str. 60.

\begin{abstract}
The cultivation of agricultural crops in a given time frame is impossible without high-performance, high-horsepower tractors. During tillage, tractor propellers have a negative effect on the soil, leading to its compaction, abrasion, and disruption of the macro-aggregate composition. This leads to wind erosion, which reduces soil fertility and crop yields. The objective of the research is to determine the change in the macro-aggregate composition of the soil and its fertility during the impact of the propellers of the K-701 and K-744 tractors. The article presents the results of field studies proving the reduction of the negative impact on the soil of the propulsion devices of twin-wheeled tractors.
\end{abstract}


This will increase the grain yield up to $24 \%$. The presented data will make it possible to carry out the optimal completing of the enterprise's tractor fleet, which ensures the minimum impact on the soil and the preservation of its fertility and yield.

Keywords. Soil fertility; high-horsepower tractor; macro-aggregate composition of the soil; crop yield.

\section{INTRODUCTION}

The cultivation of crops using intensive techniques is impossible without the use of machine-tractor units (MTU) based on high-horsepower tractors. Due to high power and productivity, MTUs perform numerous operations provided for by the crop cultivation technique and carry out multiple runs through the field. Due to the equal or multiplicity of the working width of the tillage implements, the MTU running systems move along the same tracks, exposing the soil to multiple impacts. The result is the crushing and abrasion of the upper soil layers by MTU propellers with excessive compaction of the lower soil layers, which entails the formation of erosion-hazardous macro-aggregates that increase wind erosion of soils and contribute to a decrease in crop yields. Currently, in the Saratov region, the total area of eroded agricultural land reaches 3,603.1 thousand hectares,113.5 thousand hectares of which are subject to wind erosion, and 3856.4 thousand hectares are potentially erosion-dangerous [1]. Undoubtedly, the use of high-horsepower MTUs aggravates the process of wind erosion of soil, reducing the potential soil fertility and crop yield. This requires developing a set of measures to minimize the impact of MTA propellers on the soil, thereby preserving soil fertility.

\section{MATERIALS AND METHODS.}

The objective of the research is the possibility of preserving soil fertility and increasing the yield of agricultural crops by reducing the impact of propellers of different running systems of high-horsepower tractors and determining the physical and mechanical properties of the soil, namely its macro-aggregate composition. The research was carried out in the fields of the Novouzensky district of the Saratov region. The soil type is heavy clay loam. In the course of the research, the serial layout of the propellers of the K-701 and K-744 tractors and the twin-wheeled running system were considered.

Following the tracks of the tractor propellers and at the control site, the macroaggregate composition of the soil was measured. The measurement technique involves soil sample in a $1000 \mathrm{~cm}^{3}$ cylinder. Then the soil sample was dried in air to constant weight and weighed. Then the soil sample was sieved with a set of sieves with a hole 
size of $10 ; 7 ; 3 ; 2 ; 1 ; 0.5$; and $0.25 \mathrm{~mm}$, arranged in descending order. The residue on each sieve was weighed to the nearest $0.1 \mathrm{~g}$, and after weighing, the percentage of the mass of each fraction relative to the mass of the sample was calculated. Indicators for assessing the macro-aggregate composition of the soil were determined as per the recommendation of the Agrophysical Institute using the following expressions:

soil pedality indicator

$$
\mathrm{C}=\frac{\mathrm{m}_{0,5}+\mathrm{m}_{1}+\mathrm{m}_{2}+\mathrm{m}_{3}}{\mathrm{~m}_{10}},
$$

lumpiness indicator

$$
\Gamma=\frac{\mathrm{m}_{10}+\mathrm{m}_{7}}{\mathrm{~m}_{3}+\mathrm{m}_{2}+\mathrm{m}_{1}+\mathrm{m}_{0,5}+\mathrm{m}_{0,25}},
$$

soil dispersion indicator

$$
\mathrm{P}=\frac{\mathrm{m}_{10}+\mathrm{m}_{7}+\mathrm{m}_{3}+\mathrm{m}_{2}+\mathrm{m}_{1}+\mathrm{m}_{0,5}}{\mathrm{~m}_{0,25}},
$$

where $\mathrm{m}_{10}, \mathrm{~m}_{7}, \mathrm{~m}_{3}, \mathrm{~m}_{2}, \mathrm{~m}_{1}, \mathrm{~m}_{0,5}, \mathrm{~m}_{0,25}$ are, respectively, the mass of soil in a sieve with a hole size of $10 ; 7 ; 3 ; 2 ; 1 ; 0.5$; and $0.25 \mathrm{~mm}$.

\section{LITERATURE REVIEW}

The problem of preserving soil fertility by reducing the negative impact of highhorsepower tractors on the soil is acute not only for Russia, but also for many foreign countries engaged in agricultural production. The constant increase in horsepower of tractors [2] leads to excessive soil compaction, and the presence of wide-grip tillage units contributes to an increase in the slipping of tractor propellers, leading to abrasion and crushing of the soil, leading to a decrease in soil fertility and crop yield.

Alicja Szatanik-Kloc [3] proved in his studies that after the run of high-horsepower tractors, the density of soil on the tracks of the wheels increases from $1.29 \mathrm{~g} / \mathrm{cm}^{3}$ to 1.61 $\mathrm{g} / \mathrm{cm}^{3}$, which leads to a decrease in the development of the root mass of plants and the plant itself. This leads to a decrease in the yield of grain crops up to $18 \%$.

An increase in soil density definitely contributes to a decrease in the yield of agricultural crops, and numerous runs of the propulsion devices of high-horsepower tractors along one track aggravate this process. The authors $[4,5,6]$ found that soil compaction depends not only on the weight of the tractor wheel on the axle but also on the timing and time of tillage operations. As a result of all crop cultivation operations, soil compaction reaches a depth of $1 \mathrm{~m}$ with the formation of erosion-hazardous soil particles. 
The considered studies of the authors describe the patterns and data obtained in the soil conditions of the regions where the studies were carried out. At the same time, the physical and mechanical properties of some types of soil can differ significantly, and change in different ways as a result of the impact of tractor propellers. Thus, we need to study different types of soils and correct the data obtained from the research results to get a more detailed picture of the processes occurring in the soil as a result of compaction and abrasion. The research will allow selecting the required MTU or its running system that has a lesser impact on the soil while maintaining its potential fertility.

\section{RESULTS}

To preserve the potential soil fertility and assess the degree of negative impact of the running systems of high-horsepower tractors on the soil, we conducted studies, during which the impact on the soil of different running systems of the Kirovets K-701 and K744 tractors was assessed.

The 20-year studies found that the impact of the propellers of the K-701 and K-744 tractors is negative on the potential soil fertility assessed by the humus content. The run of the propellers of the tractors leads to a decrease in the humus content in the soil in all layers compared to the control (where the soil was not affected), (Table 1). The greatest decrease in the humus content in the soil was recorded at a depth of $20 \mathrm{~cm}$ and reached $10 \%$ in comparison with the control. We established that for heavy loamy soils, the maximum permissible humus content, at which it is still possible to restore soil fertility, is $1.2-1.5 \%$ [7]

Table 1. Changes in humus content in dark brown soils in the Saratov region.

\begin{tabular}{|l|c|c|c|c|c|c|c|c|c|c|}
\hline \multicolumn{1}{|c|}{ Parameter } & \multicolumn{4}{|c|}{ Control } & \multicolumn{3}{c|}{$\begin{array}{c}\text { After soil compaction with the K-701 } \\
\text { and K-744 tractor propellers }\end{array}$} \\
\hline Depth, cm & $0-10$ & $10-20$ & $20-30$ & $30-40$ & $40-50$ & $0-10$ & $10-20$ & $20-30$ & $30-40$ & $40-50$ \\
\hline Humus content, \% & 2.3 & 2.17 & 2.04 & 1.67 & 1.28 & 2.06 & 2.14 & 1.98 & 1.67 & 1.3 \\
\hline
\end{tabular}

Thus, heavy loamy soils of the Novouzensky district of the Saratov region, due to the frequent negative impact of tractor propellers, are on the verge of no return of their fertility. An intense drop in the humus content in the root layer of the soil (to a depth of $30 \mathrm{~cm}$ ) can be due to a compaction threshold corresponding to the depth of plowing and depletion of the root mass of plants due to a lack of moisture and nutrients. Undoubtedly, this circumstance leads to a decrease in the yield of agricultural crops. 
We should also note that a decrease in the potential soil fertility occurs due to an increase in wind erosion caused by soil abrasion by tractor propellers during multiple passes. Evaluating the change in the macro-aggregate composition of the soil, we can say that all the running systems of tractors change the macro-aggregate composition of the soil, characterized by the coefficients of soil pedality, dispersion, and lumpiness (Fig. 1). It was found that the greatest change in the macro-aggregate composition of the soil was recorded as a result of the run of the propellers of the K-701 and K-744 tractors. Following the tracks of the propellers of the K-701 and K-744 serial tractors, the coefficient of soil pedality decreased in comparison with the control (intact soil) to $70.4 \%$ and $71.2 \%$.

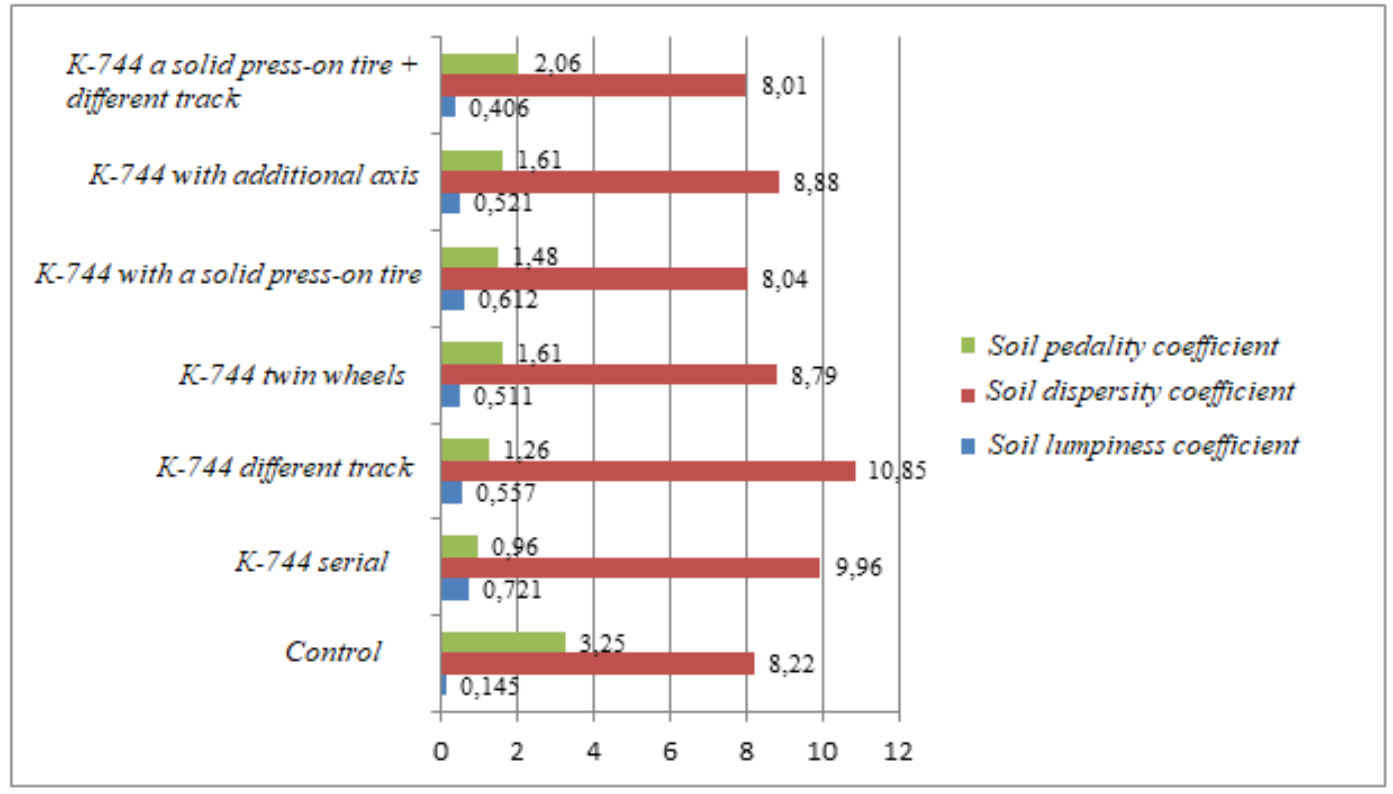

Figure 1 - Changes in the macro-aggregate composition of the soil as a result of the impact of the propulsion devices of energy-rich tractors

Other running systems of the K-744 tractor had a lesser effect on the soil and the change in the main indicator of the macro-aggregate composition of the structural coefficient in relation to the control was, respectively, for twin-wheeled tractors - up to 50.4\%; different track of front and lower wheels - up to $61.2 \%$; with a solid press-on tire - up to $54.4 \%$; with an additional support axis - up to $52.3 \%$. The least influence on the change in the coefficient of soil pedality is exerted by the running system of the tractor, consisting of different gauges of the front and rear wheels on which a solid press-on tire is installed.

A change in the coefficient of soil pedality changes other coefficients of the macroaggregate composition of the soil, such as the coefficient of lumpiness and the 
coefficient of dispersion. It is possible to assess the degree of soil crushing caused by abrasion by tractor propellers and the formation of erosion-hazardous macro-aggregates by changing the dispersion coefficient. Thus, the highest dispersion coefficient was recorded as a result of the run of the K-744 tractor with a different track of the front and rear wheels, which was $24.2 \%$ higher than the control. The slightest change in the dispersion coefficient was recorded as a result of the run of the running systems of tractors with a solid press-on tire. This circumstance can be explained by the fact that the solid press-on tire reduces the height of the wheels of the wheel propeller and reduces the volume of soil exposed to abrasion, enclosed in the interprotective space. But the use of a solid press-on tire limits the traction and coupling properties of the tractor. The increase in the dispersion coefficient recorded in all other running systems of tractors is due to an increase in the number of erosive soil particles less than 0.25 $\mathrm{mm}$ in size.

The formation of a large number of dust particles is significantly affected by soil moisture. At low moisture content of the upper soil layers, the formation of dust particles was less intense. This can be explained by the fact that with a moisture content of the upper soil layer of $8 \%$ or less, it has sufficient aggregate strength and does not collapse. At the same time, soil moisture is insufficient for the formation of larger aggregates. In deeper soil layers $5-10 \mathrm{~cm}$, the humidity becomes higher and when the wheel propeller passes, the formation of dust-like particles is more intense. However, the high moisture content of the soil after its compaction contributes to a decrease in the dispersion coefficient by an average of $13-48 \%$.

Considering the change in the lumpiness coefficient, its indicator deteriorates as a result of the run of the tractor propellers. An increase in the lumpiness of the soil is associated with the formation of lumps larger than $10 \mathrm{~mm}$. Their content in the soil after the run of the propellers of the K-744 tractor with a different running system increases by 3-4 times, which in turn leads to an increase in the coefficient by 2.3-5.2 times with a relatively low moisture content of the soil surface layers. The increase in the support area due to the doubling of the wheels reduces the normal pressure, which determines the process of formation of lumps from macro-aggregates of the soil. Obviously, the process of lump formation is largely due to the humus content in the soil and the presence of clay particles. In our opinion, the most important indicator that determines soil fertility and plant development is the content of the most valuable fractions (3-0.5 $\mathrm{mm})$.

It should be noted that the content of fractions is from 3 to $0.5 \mathrm{~mm}$, regardless of soil moisture, and is approximately at the same level in the soil in the control area and the area exposed to the tractor propeller. The percentage of reduction in the content of 
fractions from 3 to $0.5 \mathrm{~mm}$ is practically the same for all considered running systems of the tractor.

A comparative analysis of the studied running systems of the K-744 tractor found that the running system with double wheels has the slightest impact on the soil due to the change in the indicators of the macro-aggregate composition of the soil and the best traction-coupling properties. By increasing the contact area and reducing the pressure on the ground, this undercarriage has a lower impact than other systems. This also confirms the increase in the yield of spring wheat (Table 2).

Table 2. Yield and harvest structure of spring wheat.

\begin{tabular}{|c|l|c|c|c|c|c|c|c|}
\hline No. & \multicolumn{1}{|c|}{$\begin{array}{c}\text { Type of } \\
\text { tractor } \\
\text { propeller }\end{array}$} & $\begin{array}{c}\text { Years } \\
\text { of } \\
\end{array}$ & & \multicolumn{2}{|c|}{ Ytudies } \\
\cline { 6 - 8 } & & $\mathrm{dt} / \mathrm{ha}$ & $\%$ & $\begin{array}{c}\text { Number } \\
\text { of } \\
\text { productive } \\
\text { stems per } \\
1 \mathrm{~m}^{2}\end{array}$ & $\begin{array}{c}\text { Number } \\
\text { of } \\
\text { grains } \\
\text { per ear, } \\
\text { pcs. }\end{array}$ & $\begin{array}{c}\text { Weight } \\
\text { of } \\
\text { grains } \\
\text { per } \\
\text { ear, } \\
\text { pcs. } \\
\mathrm{g}\end{array}$ & $\begin{array}{c}\text { Weight } \\
\text { of } \\
1000 \\
\text { grains, } \\
\mathrm{g}\end{array}$ \\
\hline 1 & Control & 12 & 14.8 & 100 & 284 & 13.4 & 0.495 & 39.7 \\
\hline 2 & K-701 serial & 12 & 10.2 & 68.9 & 212 & 13.1 & 0.497 & 38.1 \\
\hline 3 & K-744 serial & 4 & 10.8 & 68.92 & 218 & 13.2 & 0.498 & 38.4 \\
\hline 4 & $\begin{array}{l}\text { K-701 twin- } \\
\text { wheeled }\end{array}$ & 12 & 13.5 & 91.2 & 259 & 13.5 & 0.521 & 38.9 \\
\hline 5 & $\begin{array}{l}\text { K-744 twin- } \\
\text { wheeled }\end{array}$ & 4 & 13.7 & 92.5 & 261 & 13.6 & 0.524 & 39.1 \\
\hline
\end{tabular}

The K-701 and K-744 serial tractors cause the most noticeable decrease in the yield of spring wheat that can reach up to $31 \%$ in comparison to the control. The installation of twin wheels allows increasing the yield of spring wheat up to $24 \%$ due to the less compacting and abrasive effect of the propellers on the soil.

\section{DISCUSSION}

The results of the research were reported at scientific conferences and annual reports on research conducted at Saratov State Agrarian University. 


\section{CONCLUSION}

To preserve soil fertility, changes in the indicators of the macro-aggregate composition of the soil were determined after the passes of different running systems of highhorsepower tractors. The data of experimental studies showed that the running system of the K-744 twin-wheeled tractor has the least effect on the soil. The use of twin wheels on high-horsepower tractors for soil cultivation allows maintaining soil fertility and, as a result, increasing the yield of grain crops.

\section{REFERENCES}

[1] Gagina I.S. The problem of soil erosion in the Saratov region / Gagina I.S., Vasiliev D.I. // Collection: Achievements and prospects of scientific and innovative development of the agroindustrial complex. Proceedings of the AllRussian (national) scientific-practical conference with international participation. Under the general editorship of Mikolaichik I.N. Kurgan, 2020. P. 37-40.

[2] Keller T. Historical increase in agricultural machinery weights enhanced soil stress levels and adversely affected soil functioning / Keller T., Sandin M., Colombi T., Horn R., Or D. // Soil \& Tillage Research. 2019. V. 194. P. 104-293.

[3] Alicja Szatanik-Kloc Soil compaction-induced changes of physicochemical properties of cereal roots / Alicja Szatanik-Kloc, Rainer Horn, Jerzy Lipiec, Anna Siczek, Justyna Szerement // Soil \& Tillage Research. 2018. V. 175. P. 226-233.

[4] Obour P.B. Subsoil compaction assessed by visual evaluation and laboratory methods / Obour P.B., Schjønning P., Peng Y., Munkholm L.J.// Soil \& Tillage Research. 2017. V. 173. P. 4-14.

[5] Peter Bilson Obour Compaction and sowing date change soil physical properties and crop yield in a loamy temperate soil/ Peter Bilson Obour, Dorothee Kolberg, Mathieu Lamandé, Trond Børresen // Soil \& Tillage Research. 2018. V. 184. P. 153-163.

[6] Raguiara P. Silva Numerical modeling of soil compaction in a sugarcane crop using the finite element method / Raguiara P. Silva, Mário M. Rolim, Igor F. Gomes, Elvira M.R. Pedrosa // Soil \& Tillage Research. 2018. V. 181. P. 1-10.

[7] Sharkov I.N. The effect of agrotechnical techniques on the change in the content of humus in arable soils / Sharkov I.N., Danilova A.A. // Agrochemistry. 2010. No. 12. P. 72-81. 